\title{
Entrevista com a fundadora da ABRAPEE Prof. Dra. Solange Múglia Wechsler
}

SOLANGE MUGLIA WECHSLER é psicóloga, formada pela PUC-Rio de Janeiro, com mestrado em Psicologia Escolar e doutorado em Psicologia Educacional pela University of Georgia (Estados Unidos), possuindo também vários cursos em nível de pós-doutoramento no exterior. Foi docente da PUC-Rio, Universidade Gama Filho e, durante vários anos, da Universidade de Brasília, encontrando-se atualmente ligada ao programa de pós-graduação em Psicologia da Pontificia Universidade Católica de Campinas.

É coordenadora do Laboratório de Avaliação e Medidas Psicológicas-LAMP e dirige o Centro Nacional de Criatividade e Desenvolvimento Humano-CRIADH. É pesquisadora de nível I pelo CNPQ. Possui vários trabalhos publicados no Brasil e no exterior, ressaltando-se os livros: Criatividade:descobrindo e encorajando, Psicologia escolar: pesquisa, formação e prática e $O$ desenho da figura humana: avaliação do desenvolvimento cognitivo infantil.

Foi a fundadora e primeira presidente da ABRAPEE. Criou também o Comitê Ibero-Latino de Psicologia Escolar dentro da Associação Internacional de Psicologia Escolar. Fez parte do grupo fundador da Asociación Internacional para el Desarollo de la Creatividad. Contribui no comitê editorial da Revista Ibero-Americana de Diagnóstico y Evaluación Psicológica e da revista Estudos de Psicologia. Recebeu o título honorário como Creative Scholar (Pesquisador Criativo) nos Estados Unidos, e de "Personalidad Destacada en Artes y Ciencias" na Venezuela.

\section{Entrevistadora:}

Dra. Geraldina Porto Witter

\section{Como surgiu a idéia da ABRAPEE?}

A importância da Psicologia Escolar só surgiu para mim durante a pós-graduação nos Estados Unidos. Recebi, aqui no Brasil, durante a minha graduação (1970-1974), a formação tradicional como psicóloga, no qual a Psicologia Escolar era somente dada em forma de uma única matéria, sem muita importância, pois a prevalência era, como ainda continua sendo hoje em muitos locais, para a área clínica. Assim sendo, foi somente durante o meu mestrado e doutorado (19761981) que despertei para a Psicologia Escolar e pude entender a sua abrangência como área de atuação e a sua relevância para o psicólogo brasileiro.

Este sentimento de desconforto ou melhor, inconformismo, persistiu em mim durante os meus primeiros anos de volta ao Brasil. Nesta ocasião recebi um pedido, do editor da revista School Psychology International, para escrever um artigo sobre a Psicologia Escolar no Brasil. Foi este o meu primeiro artigo sobre Psicologia Escolar, publicado em 1986 por este periódico, que levantou curiosidade a respeito da nossa realidade e que fez que o Dr. Thomas Oak1and, que trabalhava na University of Texas, me escrevesse demonstrando o seu interesse em conhecer a Psicologia Escolar brasileira.

A visita do Dr. Oakland à Universidade de Brasília, onde eu me encontrava trabalhando nesta época, foi uma excelente oportunidade para clarificar a minha visão, ou melhor, o meu sonho para a Psicologia Escolar no Brasil. Pude então discutir, com um especialista de renomada experiência, os parâmetros internacionais que estavam orientando a formação e atuação do psicólogo escolar em vários países, padrões estes que poderiam servir de guia para elaborar uma proposta de estatuto para uma Associação em Psicologia Escolar. Foi assim que nasceu a idéia da ABRAPEE. 
2. Quais foram os passos e as dificuldades que você encontrou para conseguir que a idéia da ABRAPEE se tomasse uma realidade?

As dificuldades maiores, interessantemente, foram encontradas dentro da nossa própria categoria que discutia, como até hoje discute, quem é o psicólogo escolar. A Associação deveria de Psicologia Escolar, de Psicologia Educacional, ou de ambas? Qual seria a distinção entre estas áreas? E os educadores que trabalham também com o processo psicoeducativo, seriam também incluidos? Estas foram as questões mais debatidas durante as Reuniões Anuais da Sociedade de Psicologia de Ribeirão Preto, em 1987 e 1988, quando se discutia a proposta para a nossa Associação. Finalmente decidimos que a Associação incluiria as duas denominações, Psicologia Escolar e Educacional, utilizando-se as definições internacionais para estas áreas de atuação, que foram posteriormente publicadas nos estatutos da ABRAPEE, enfocando-se o aspecto da atuação e da pesquisa. Assim sendo, surgiu a nossa denominação atual: Associação de Psicologia Escolar e Educacinal-ABRAPEE. Outra decisão foi também a de ter a participação dos educadores, como membros associados, porém sem fazer parte da diretoria, tendo visto que esta era uma identidade de classe para os psicólogos.

Uma grande dúvida ,nos debates entre os profissionais, sobre a formação da ABRAPEE era se esta deveria ser uma única entidade,de caráter nacional, ou se deveria ser composta por seções estaduais e uma federal, semelhante à organização do Conselho Federal de Psicologia desta época. Decidiu-se que os estados que estivessem prontos deveriam criar as suas seções de ABRAPEE, fazendo as suas modificações necessárias no estatuto básico da ABRAPEE. Assim sendo, em dezembro de 1988, fundei, com o grupo de profissionais em Psicologia Escolar e educacional da rede pública de Brasília, a seção ABRAPEE-DF. Em seguida, veio a fundação da seção ABRAPEESP, em maio de 1989, pela Dra. Raquel Souza Lobo Guzzo. Outros grupos da ABRAPEE se abriram, posteriormente, em vários estados, não tendo, entretanto, se constituido formalmente em seções, que foram em Minas Gerais, com a Dra. Eulalia Maimoni, no Pará, com a Dra. Raquel Bechara e no Rio de Janeiro, com a Dra. Vera Gomes.

Finalmente, em 1991, a ABRAPEE realizou o seu marco histórico, ao organizar o I Congresso Nacional de Psicologia Escolar, sediado em Valinhos (SP).Nesta oportunidade, decidiuse que deveria haver uma entidade nacional para congregar os diferentes estados e possibilitar a participação de profissionais que não possuiam nenhum grupo de referência em seu local de moradia. Surgiu assim a ABRAPEE-NACIONAL.

\section{Na sua avaliação, qual é o impacto da ABRAPEE desde a sua criação até o presente momento?}

Penso que a ABRAPEE teve grande impacto desde o primeiro momento da sua criação. Não se acreditava, entre os próprios profissionais, na força da Psicologia Escolar no país, ou melhor, não se conhecia a existência de tantos profissionais que trabalhavam com a Psicologia Escolar no Brasil. Portanto, a grande surpresa foi dada no número de pessoas inscritas no I Congresso Nacional da ABRAPEE em 1991, e depois, no II Congresso Nacional da ABRAPEE, em 1994, realizado junto com o XVII Congresso Internacional de Psicologia Escolar. No primeiro, tivemos quatrocentas pessoas, e no segundo, quase mil participantes, entre profissionais brasileiros e estrangeiros. A qualidade dos trabalhos inscritos nestes dois eventos demonstrou que os profissionais estavam bastante avançados na sua discussão sobre a identidade e a prática do psicólogo escolar escolar brasileiro, temas estes que ficaram bem registrados nos Anais destes dois congressos, e que têm servido como livros-textos em vários cursos do país.

As publicações da ABRAPEE se tomaram necessárias a partir destes momentos, e o Informativo Nacional (semestral) e o de São Paulo (mensal) estão se tomando, cada vez mais, 
fontes de consulta para classe. Justifica-se agora, mais do que nunca, uma revista científica dedicada exclusivamente à Psicologia Escolar, e a ABRAPEE vem atender assim a este pedido na forma desta revista agora lançada.

A ABRAPEE também se preocupa com o resgate da nossa história e com a continuidade dos esforços na nossa luta pela melhoria da área. Para exemplificar, na composição da sua diretoria, a ABRAPEE tem sempre três presidentes: o passado, o presente e o futuro. Desta maneira, evita-se ruturas nas linhas de ação de cada presidente que a ABRAPEE possa vir a ter. Na fundação da ABRAPEE, em respeito a nossa história, foi eleita como presidente passado, em cargo honorário, a Dra. Maria Helena Novaes, uma das pioneiras do movimento da Psicologia Escolar Brasileira. Assumi como presidente atual e a Dra. Raquel Souza Lobo Guzzo como presidente futura. Na segunda diretoria, já em fase de término de mandato agora em 1986, estou como presidente passado, a Dra. Raquel Guzzo como atual e a senhora, Dra. Geraldina, como presidente futura. Esta composição de presidência deverá sempre seguir assim, como definida pelo estatuto da ABRAPEE, à maneira como acontece nas associações internacionais renomadas como a American Psychological Association (APA) ou a Internatinal School Psychology Association (ISPA).

\section{Como você vê o futuro da ABRAPEE e da Psicologia Escolar no Brasil?}

Acredito que a ABRAPEE deu um passo decisivo na história da Psicologia Escolar no Brasil, um ponto onde não existe mais retomo. Está mais que demonstrado que a Psicologia Escolar é uma área importantíssima para o país e que muitos profissionais estão trabalhando com e por ela.

Quero ressaltar, entretanto, que a ABRAPEE ainda é uma criança, ela tem apenas cinco anos de idade. Muitas serão as crises de adolescência, durante o seu desenvolvimento, que a ABRAPEE ainda vai ter que vencer. Várias batalhas terão que ser realizadas, para a melhoria da qualificação do profissional da área, para o aumento da produção científica voltada para a realidade do nosso país,e para o reconhecimento legal da presença do psicólogo na escola. Porém, tudo isto vai depender da união da nossa categoria, assim como existe na área da psicologia clínica.

O psicólogo escolar deverá, durante este percurso, ter uma visão mais abrangente do seu próprio campo de trabalho, pois a sua atuação não se restringe somente ao prédio de uma escola mas a todos ambientes onde possam ocorrer processos educacionais. É desta maneira que está sendo entendida a psicologia escolar e educacional em termos internacionais.

\section{Como você vê a produção científica em Psicologia Escolar no Brasil?}

A nossa produção científica está ainda bastante voltada para o primeiro grau, escolas públicas e classes regulares. Temos uma enorme deficiência de informações no que concerne às classes especiais, às escolas particulares e outros níveis de escolaridade. A área da avaliação psicológica necessita também ser mais pesquisada afim de oferecer subsídios para a prática do profissional brasileiro. Faltam publicações em português, pois a maioria dos nossos psicólogos escolares não lêem em inglês e não podem, portanto, se atualizar com a literatura recente. Este quadro é ainda mais agravado ao se constatar que poucos são os psicólogos que assinam periódicos, freqüentam congressos ou investem em si mesmos para uma reciclagem. Tudo isto, como seria de se esperar, atrasa, de uma maneira lamentável. o nosso movimento em prol da melhoria da Psicologia Escolar brasileira.

\section{Em que acha relevante a ABRAPEE investir no futuro próximo?}

A ABRAPEE deve fazer um esforço contínuo na área política, assim como acontece com as associações no exterior. Podemos observar que a maioria das associações internacionais em Psicologia Escolar possue representantes nas comissões de educação do poder legislativo, afim de 
observar e estar presente nas decisões que possam afetar a prática do profissional em educação. No plano científico, a ABRAPEE deve continuar a estimular a produção na área e oferecer oportunidades para a reciclagem através dos seus congressos bi-anuais. $\mathrm{O}$ seu investimento em publicação deve abranger não só os informativos, anais de congresso ou revista científica, mas também livros, manuais e guias com propostas de atuação.

A ABRAPEE também deve investir em relações públicas afim de tomar mais visível o trabalho do psicólogo escolar/educacional. Os diversos setores envolvidos com a educação devem entender a importância do profissional de psicologia na equipe escolar. Não há dúvidas, a luta é grande, dentro e fora da classe. Entretanto. quero ressaltar que a luta não é só nossa, ela também existe em outros países, como podemos observar nos congressos internacionais em Psicologia Escolar. As nossas dúvidas e dificuldades estão também sendo discutidas por profissionais de diversas nações. Portanto, não estamos só, temos que lutar por um ideal e uma visão de Psicologia Escolar e Educacional que é partilhada mundialmente. 